\title{
Effective implementation of a protocol on initial stabilization of preterm neonates delivered at less than 32 weeks gestation through a simulation programme in a District General Hospital
}

\author{
*H M D Herath ${ }^{1}$, S Somarathna ${ }^{1}$, D S Rajapaksha ${ }^{2}$, P Dissanayaka ${ }^{3}$, G W C Malkanthi ${ }^{3}$, G Ruwan \\ Kumara $^{3}$
}

Sri Lanka Journal of Child Health, 2016; 45(4): 259-263

\begin{abstract}
Background: Effective initial stabilization of preterm neonates in the initial 60 minutes of life (termed neonatal golden hour) helps minimize complications such as intraventricular haemorrhage and chronic lung disease and leads to improved prognosis. Effective resuscitation, respiratory support, maintaining normal temperature and blood sugar, timely parenteral nutrition, timely treatment of sepsis and a completed admission within 60 minutes of delivery are identified as key components of the golden hour. High intensity and multitude of interventions necessary for initial stabilization, performed by a staff that lacks uniform training make golden hour a challenging task. A protocol can provide a care pathway on the essential steps of the golden hour. Simulationbased learning to practise the protocol has been identified as way to create a cohesive team.
\end{abstract}

Objectives: To evaluate effective implementation of a protocol on initial stabilization of preterm neonates delivered at less than 32 weeks gestation through a simulation programme.

Study design: Prospective study

Method: The extent to which the key components of neonatal golden hour were achieved before and after implementation of the protocol were assessed using a checklist.

Results: In the post-protocol group a significant increase was seen in the number of infants resuscitated with optimal preparation and attended

$\overline{{ }^{1} \text { Consultant Paediatrician, District General }}$ Hospital, Hambantota, ${ }^{2}$ Medical Officer, Lady Ridgeway Hospital for Children, Colombo, ${ }^{3}$ Medical Officer, District General Hospital, Hambantota.

*Correspondence:durgaherath@gmail.com

(Received on 05 January 2015: Accepted after revision on 19 February 2015)

The authors declare that there are no conflicts of interest.

Personal funding was used for the project.

Open Access Article published under the Creative

Commons Attribution CC-BY (cc) (P) License. by a senior member of staff $(\mathrm{p}<0.05)$, the number of infants who received intravenous glucose infusion and antibiotics $(\mathrm{p}<0.01)$, the number of infants with blood sugar more than $2.6 \mathrm{mmol} / 1$ in 1 hour $(p<0.05)$ and the number of infants with completed admission within 1 hour $(\mathrm{p}<0.01)$. There was a statistically significant difference in adherence to thermo-protective measures during stabilization $(\mathrm{p}<0.01)$, and the number of neonates with temperature above $36.5^{\circ} \mathrm{C}$ on admission $(\mathrm{p}<0.01)$ in the post-protocol group.

Conclusions: Implementation of the golden hour protocol through a simulation programme can significantly improve the stabilization of infants delivered at less than 32 weeks gestation.

DOI: http://dx.doi.org/10.4038/sljch.v45i4. 8183

(Key words: neonatal golden hour, initial stabilization, preterm neonates, simulation)

\section{Background}

Preterm birth is a leading cause of neonatal mortality and morbidity. Poor outcomes result from sepsis, intraventricular haemorrhage (IVH), necrotizing enterocolitis (NEC), chronic lung disease (CLD) and retinopathy of prematurity (ROP). Studies have shown that effective initial stabilization aimed to complete within 60 minutes of birth help in minimizing these complications and lead to improved outcomes. The first 60 minutes after birth is hence named neonatal golden hour ${ }^{1-5}$. The following are identified as the key components of the neonatal golden hour ${ }^{5}$ :

1. Resuscitation and respiratory support

2. Maintaining normal temperature and blood sugar

3. Timely parenteral nutrition administration

4. Rapid treatment of sepsis

5. Completed admission within 60 minutes of delivery

To achieve all these goals the team members must act in a coordinated manner and have assigned roles. The high intensity and dynamic situation in stabilizing neonates and the multitude of tasks involved make it a difficult task. Lack of uniformity of skills and knowledge of the staff 
involved make it difficult to offer consistent organized care. A protocol can provide the "road map" on essential steps of the golden hour. Hence each patient is cared for in the same process, allowing for fewer mistakes and better outcomes.

Use of simulation-based learning to practise the protocol in a safe environment has been identified as a way to create a cohesive team ${ }^{6,7}$. Simulation allows the team to utilize the same equipment, practise teamwork and streamline the process in a realistic setting prior to use on a patient. Through facilitated debriefing, team members identify errors as well as communication opportunities and make corrections to their practice.

\section{Objectives}

The primary objective was to evaluate effective implementation of a protocol on initial stabilization of preterm neonates delivered at less than 32 weeks gestation through a simulation programme. Specific objectives were to compare the extent to which key components of the neonatal golden hour were achieved before and after introduction of the protocol.

\section{Method}

A prospective interventional study was carried out in the neonatal intensive care unit (NICU) of Hambantota District General Hospital from January 2014 to June 2015. It is a 16 bedded unit with 4 ventilated beds. Annual delivery rate in the hospital is 3000. The staff comprised 2 consultant paediatricians who are trainers in neonatal life support (NLS), 5 medical officers trained in NLS, 3 intern house officers with no NLS training and 16 nurses with a diploma in nursing but no training in NLS. Fifty eight neonates were assigned to the preprotocol group and 64 neonates to the post-protocol group after obtaining parental consent. All preprotocol neonates were recruited before commencing the post-protocol neonates. The following areas of neonatal stabilization were assessed at each delivery of a preterm neonate less than 32 weeks gestation using a checklist completed by one of the researchers:

1. Availability of all necessary resuscitative equipment at site of delivery which were pre-checked (as per Sri Lanka NLS course manual).

2. Attendance of a senior staff member for delivery (senior house officer/consultant trained in NLS).

3. Adherence to NLS algorithm during resuscitation.

4. Use of surfactant prophylactically in gestation less than 26 weeks, and as rescue treatment within 1 hour if oxygen demand is more than $30 \%$
5. Oxygen saturation at 10 minutes of birth. Eighty five percent was considered the lowest normal value.

6. Use of thermos-protective measures (hat, dry warm towels, plastic bag, radiant warmer, pre-warmed humidified incubator) throughout resuscitation, transport and stabilization

7. Axillary temperature on admission; $36.5^{\circ} \mathrm{C}$ was considered the lowest normal value.

8. Time taken from birth to administer IV fluids infusion and antibiotics

9. Random blood sugar within 1 hour of birth; $2.6 \mathrm{mmol} / 1$ was considered the lowest normal value

10. Time taken to complete admission

A protocol on early stabilization of very preterm neonates was developed, based on the position statement published by the British Association of Perinatal Medicine, 2005 ${ }^{8}$, American Neonatal Resuscitation Programme ${ }^{9}$, European Consensus Guidelines on the Management of Neonatal Respiratory Distress Syndrome ${ }^{10}$ and some guidelines used by British Neonatal Networks (Table 1).

The protocol was introduced to medical, nursing and minor staff of neonatal unit (NNU), General Hospital Hambantota in the form of a lecture. The lecture comprised the special requirements of preterm neonates, key areas of neonatal golden hour stabilization, behavioural skills such as assigning roles, effective communication, delegation and call for help. A questionnaire with multiple choice questions at the end of the lecture was used to ensure that key areas of stabilization were understood by participants. This was followed by practical training sessions comprising a scenario teaching (using mannequins) of an extreme preterm extreme low birth weight neonate. Each staff member was given the opportunity to resuscitate and stabilize the preterm neonate followed by a debriefing session. The above areas of neonatal stabilization were assessed in the neonates born in post-protocol time period using a checklist completed by one of the researchers.

Statistical analysis was conducted using SPSS version 16. Statistical significance between preand post-protocol observations was assessed using Chi-Square test for discrete categorical variables and ANOVA for continuous variables. A $p$ value less than 0.05 was considered significant. Ethical approval was obtained from the ethical review committee of the Sri Lanka College of Paediatricians 
Table 1: Protocol on early stabilization of preterm neonates 32 weeks or less

\begin{tabular}{|c|c|c|}
\hline & Preparation/ duties of doctors & Preparation/ duties of nurses \\
\hline \multirow{8}{*}{ Before birth } & \multicolumn{2}{|c|}{ Communicate with labour room regarding impending preterm deliveries } \\
\hline & Warm resuscitaire & Decide who is responsible for the admission \\
\hline & $\begin{array}{l}\text { Small endotracheal tubes (ETTs), } \\
\text { laryngoscope, adhesive tapes }\end{array}$ & Prepare warm incubator \\
\hline & Check Ambu bag and oxygen & Prepare ventilator /Ambu/ Suction \\
\hline & Check suction apparatus & $\begin{array}{l}\text { Prepare monitors (saturation, heart rate (HR), } \\
\text { temperature, blood pressure) }\end{array}$ \\
\hline & Warm towels & Prepare infusions (10\% Dextrose ) \\
\hline & Surfactant $(<27+6$ weeks $)$ & Scales \\
\hline & Polythene bags & Prepare equipment to transfer baby \\
\hline \multirow{5}{*}{ At delivery } & Place baby in plastic bag & $\begin{array}{l}\text { Assist with resuscitation } \\
\text { Help with ETT fixation }\end{array}$ \\
\hline & $\begin{array}{l}\text { Open airway with inflation breaths - see HR } \\
\text { rise } \\
\text { Continue ventilation breaths }\end{array}$ & Keep baby warm \\
\hline & $\begin{array}{l}\text { Intubate }- \text { where appropriate } \\
\text { Check ETT position }\end{array}$ & Set up Transfer equipment \\
\hline & Continue gentle ventilation & Assist with transfer to transport incubator \\
\hline & Consider cardiac massage, drugs if needed & Apply oxygen saturation monitor \\
\hline \multirow{6}{*}{$\begin{array}{l}\text { On arrival } \\
\text { in neonatal } \\
\text { unit }\end{array}$} & Check / Adjust ventilation & Weigh the baby \\
\hline & Prepare surfactant if not given already & Transfer to incubator in plastic bag \\
\hline & Prescribe drugs \& fluids & Connect to ventilator - reassess A B C \\
\hline & \multirow[t]{3}{*}{ Write blood test forms } & Measure temperature \\
\hline & & Attach saturation and temperature probes \\
\hline & & Baseline observations \\
\hline \multirow{5}{*}{$\begin{array}{l}\text { 5-30 minutes } \\
\text { after arrival }\end{array}$} & Insert intravenous (IV) cannula & Vitamin K \\
\hline & Early capillary gas and glucose & Ensure IV and intra-arterial (IA) fluids ready \\
\hline & $\begin{array}{l}\text { Take blood culture, full blood count, clotting, } \\
\text { Group, direct Coombs test, glucose }\end{array}$ & IV access, Start infusions \\
\hline & \multirow[t]{2}{*}{ Give surfactant } & $\begin{array}{l}\text { Monitor oxygen saturation, } \mathrm{HR} \text { and } \\
\text { temperature }\end{array}$ \\
\hline & & Assist with positioning for X-Rays \\
\hline \multirow{8}{*}{$\begin{array}{l}30-60 \\
\text { minutes } \\
\text { after arrival }\end{array}$} & $\begin{array}{l}\text { Review ventilation with gases and oxygen } \\
\text { saturations }\end{array}$ & $\begin{array}{l}\text { Umbilical venous catheter (UVC)/ Umbilical } \\
\text { arterial catheter (UAC) if possible }\end{array}$ \\
\hline & Treat hypoglycaemia - if present & Monitor saturations, HR, temperature \\
\hline & Treat hypotension - if present & Set up opiate infusion - if required \\
\hline & $\begin{array}{l}\text { Request chest } \mathrm{x} \text {-ray and abdominal x-ray - do } \\
\text { not wait for } 4 \text { hours }\end{array}$ & \multirow[t]{4}{*}{$\begin{array}{l}\text { Do not remove plastic bag until temperature } \\
\text { stable }\end{array}$} \\
\hline & Sedation & \\
\hline & Ensure antibiotics and Vitamin $\mathrm{K}$ given & \\
\hline & UAC/UVC if necessary & \\
\hline & \multicolumn{2}{|c|}{$\begin{array}{c}\text { The first hour is up } \\
\text { Once the baby is set up, Hands Off-Eyes on! }\end{array}$} \\
\hline
\end{tabular}

\section{Results}

Data for a total of 122 preterm infants were reviewed, $58(47.5 \%)$ in the pre-protocol group and $64(52.4 \%)$ in the post-protocol group. Three neonates in the pre-protocol group and 2 neonates in the post-protocol group were not included as parental consent was not obtained. There was no significant difference in demographic data between the two groups as shown in Table 1. Data for resuscitation and respiratory support are shown in Table 2. Data for maintaining normal temperature and blood sugar are shown in Table 3. Data for administration of dextrose, antibiotics and vitamin $\mathrm{K}$ are shown in Table 4. 
Table 1: Demographic data

\begin{tabular}{|l|c|c|c|}
\hline \multicolumn{1}{|c|}{ Demographic data } & Pre-protocol & Post-protocol & P value \\
\hline Birth weight & Mean 1168.8 SD 251.5 & Mean 1190.2 SD 232.3 & 0.627 \\
\hline Gestation & Mean 29.90 SD & Mean 30.0 SD 1.85 & 0.708 \\
\hline Male: female ratio & $28: 30$ & $31 / 30$ & 0.239 \\
\hline Vaginal delivery & No. 42 $(72.4 \%)$ & No. $40(62.5 \%)$ & 0.244 \\
\hline Cesarean section & No. $16(27.6 \%)$ & No. $24(37.5)$ & 0.244 \\
\hline Antenatal steroid received & No. $27(46.6 \%)$ & No. 33 $(51.6 \%)$ & 0.58 \\
\hline
\end{tabular}

Table 2: Resuscitation and respiratory support

\begin{tabular}{|c|c|c|c|}
\hline & $\begin{array}{c}\text { Pre protocol } \\
\text { No. }(\%)\end{array}$ & $\begin{array}{c}\text { Post protocol } \\
\text { No. }(\%) \\
\end{array}$ & P value \\
\hline Availability of pre-checked resuscitation equipment on site & $82.8 \%$ & $96.9 \%$ & 0.013 \\
\hline Attendance of senior medical staff (SHO/consultant) & $74.1 \%$ & $90.6 \%$ & 0.018 \\
\hline Adherence to NLS guideline & $94.8 \%$ & $96.9 \%$ & 0.569 \\
\hline Intubation / surfactant as indicated & $68.4 \%$ & $92.9 \%$ & 0.090 \\
\hline Saturation $>85 \%$ at 10 minutes & $79.3 \%$ & $92.2 \%$ & 0.065 \\
\hline
\end{tabular}

Table 3: Maintaining normal temperature and blood sugar

\begin{tabular}{|l|c|c|c|}
\hline & $\begin{array}{c}\text { Pre protocol } \\
\text { No. (\%) }\end{array}$ & $\begin{array}{c}\text { Post protocol } \\
\text { No. (\%) }\end{array}$ & P value \\
\hline Use of warming methods of newborn at all times & $65.5 \%$ & $92.2 \%$ & 0.001 \\
\hline Axillary temperature on admission $>36.5^{0} \mathrm{C}$ & $60.3 \%$ & $84.4 \%$ & 0.004 \\
\hline CBS $>2.6 \mathrm{mmol} / 1$ within 1 hour of birth & $65.5 \%$ & $84.4 \%$ & 0.021 \\
\hline
\end{tabular}

Table 4: Administration of dextrose, antibiotics and Vitamin $\mathrm{K}$

\begin{tabular}{|l|c|c|c|}
\hline & $\begin{array}{c}\text { Pre protocol } \\
\text { No. (\%) }\end{array}$ & $\begin{array}{c}\text { Post protocol } \\
\text { No. (\%) }\end{array}$ & P value \\
\hline Administration of intravenous fluids within 1 hour & $65.5 \%$ & $93.8 \%$ & 0.000 \\
\hline Administration of antibiotics within 1 hour & $65.5 \%$ & $90.6 \%$ & 0.001 \\
\hline Vitamin K within 1 hour & $93.1 \%$ & $100.0 \%$ & 0.048 \\
\hline Completed admission within 60 minutes & $60.3 \%$ & $82.8 \%$ & 0.008 \\
\hline
\end{tabular}

\section{Discussion}

Our study demonstrated significant improvement in preparation for resuscitation, higher rates of early surfactant administration and better oxygen saturation at 10 minutes following implementation of the protocol. It showed better adherence to thermo-protection resulting in better axillary temperature on admission. Further, it showed improved rates of IV fluid and antibiotic administration, better random blood sugar within 1 hour of birth and higher rates of completing admission within 1 hour.

Several studies have been done on implementation of the protocol on golden hour as part of quality improvement projects. Ashmede et al. demonstrated improved surfactant administration, dextrose and aminoacid infusion, body temperature at admission, odds of developing chronic lung disease, and odds of developing ROP following implementation of the project ${ }^{11}$. Wallingford $\mathrm{B}$ et al concentrated extensively on strategies to prevent CLD, thermoregulation and team work ${ }^{3}$. This study showed increasing compliance with the goldenhour practices and decreased incidence of CLD. Finer et al reported improved resuscitation of preterm neonates following use of video recordings to look at the use of oxygen, effectiveness of bag and mask ventilation, intubation in the delivery area and communication among team members ${ }^{12}$. These studies have used lectures, posters, emails and training sessions to introduce the protocol. None mention the educational background of the staff involved. None have studied the sustainability of improvement achieved. Our study concentrated on achievement of all key components of neonatal golden hour described by Doyle and Vermont Oxford Network. The principal method of training was a simulation programme where every staff member had the opportunity to be trained and evaluated. Effective resuscitation needs optimal preparation, availability of appropriate senior help and adhering to standard resuscitation guidelines.

Limitations of the study include non-assessment of secondary outcomes such as CLD, ROP and IVH and non-evaluation of the sustainability of results obtained.

\section{Conclusion}

Implementation of the Golden Hour Protocol through a simulation programme can significantly 
improve the stabilization of infants delivered at less than 32 weeks gestation.

\section{Acknowledgements}

We thank Dr. Padmal Silva, Consultant Community Physician, Department of Research, National Institute of Health Sciences for the statistical analysis of data. We thank Dr. K. K. Hemantha, Consultant Paediatrician DGH Hambantota for assistance in simulation sessions.

\section{References}

1. Costeloe $\mathrm{K}$ et al. The EPICure study: outcomes to discharge from hospital for infants born at the threshold of viability. Pediatrics 2000; 106:659-71. http://dx.doi.org/10.1542/peds.106.4.659 PMid: 11015506

2. Acolet D et al. Project 27/28: Inquiry into quality of neonatal care and its effect on the survival of infants who were born at 27 and 28 weeks in England, Wales, and Northern Ireland. Pediatrics 2005; 116(6):1457-65. http://dx.doi.org/10.1542/peds.2004-2691 PMid: 16322171

3. Wallingford B et al. Implementation and evaluation of "Golden Hour" Practices in infants younger than 33 weeks' gestation. Newborn and Infant Nursing Reviews 2012; 12(2):86-96.

http://dx.doi.org/10.1053/j.nainr.2012.03.0 08

4. Bissinger RL et al. Thermoregulation in very low-birth-weight infants during the golden hour, results and implications: Advances in Neonatal Care 2010; 10(5):230-8.

http://dx.doi.org/10.1097/ANC.0b013e318 1f0ae63

PMid: 20838071

5. Doyle K, Bradshaw W. Sixty golden minutes: Neonatal Network 2012; 31(5):289-94.

http://dx.doi.org/10.1891/07300832.31.5.2

89

PMid: 22908049
6. Fernandez R et al. Toward a definition of teamwork in emergency medicine. Academic Emergency Medicine 2008; 15(11):1104-12.

http://dx.doi.org/10.1111/j.15532712.2008 $.00250 . x$

PMid: 18828831

7. Chakravarthy B et al. Simulation in Medical School Education: Review for Emergency Medicine West Journal of Emergency Medicine 2011; 12(4): 461-6. http://dx.doi.org/10.5811/westjem.2010.10 .1909

PMid: 22224138 PMCid: PMC3236168

8. Early care of new-born infant, statement on current level of evidence: British Association of Perinatal medicine, 200516.Pediatrics2000; 106 (4): 623.

http://dx.doi.org/10.1542/peds.106.4.623

9. Barakaldo. The ENS Project. Infant: the evidence basis for current practice. Pediatric Research 2009; 65:375-80. http://dx.doi.org/10.1203/PDR.0b013e318 199386a

PMid: 19127213

10. David G .European Consensus Guidelines on the Management of Neonatal Respiratory DistressSyndrome in Preterm Infants - 2013 Update

11. Ashmeade TL et al. Outcomes of a neonatal Golden hour Implementation project. American Journal of Medical Quality $2014 \quad$ Sep 5 Pii: 1062860614548888. [Epub ahead of print] PMid: 25194002

12. Finer $\mathrm{N}$, Rich $\mathrm{W}$. Neonatal resuscitation for the preterm infant: evidence versus practice. Journal of Perinatology 2010; 30: S57-S66.

http://dx.doi.org/10.1038/jp.2010.115

PMid: 20877409 